\title{
EL POLEN DE PAULLINIEAE (SAPINDACEAE)
}

por MARIA S. FERRUCCI' y LUISA M. ANZOTEGUI²

\section{Summary}

A detailed study on the morphology of pollen on t.nirty one species of the tribe Paullinieae, comprising seven genera, has been carried out by LM and SEM.

The pollen grains of the following taxa were examined: subtribe Paulliniinae (Cardiospermum L., 4 spp., Houssayanthus Hunz., 2 spp., Lophostigma Radlk., I sp., Paullinia L., 3 spp., Serjania Miller, 16 spp., and Urvillea Kunth, 4 spp.); subtribe Thinouiinae (Thinouia Triana \& Planchon, 1 sp.). All of them grow in Argentina, except L. plumosum Radlk. and H. monogynus (Schdl.) Ferrucci, collected in Bolivia and Paraguay respectively.

Four pollen types have been recognized: type A - isopolar, tricolporate, subspheroidal to oblate-spheroidal grains in Thinouia; type B - isopolar or subisopolar, trisyncolporate, heterocolpate, dicolpodiorate, monocolpate, prolate or prolate-spheroidal grains in Lophostigma; type C - heteropolar, hemitrisyncolporate, peroblate or oblate grains are shared by Serjania, Houssayanthus, Cardiospermum and Urvillea, (in these genera three groups are recognized based on details of structure and sculpture) and type D - isopolar or subisopolar triporate, oblate or peroblate grains in Paullinia.

The probable evolutionary trends of pollen morphology characters are discussed. Based on shape and aperture types of the grains, a tentative phylogenetic line of the tribe is presented.

Miembro de la Carrera del Investigador Científico y Tecnológico, CONICET Instituto de Botánica del Nordeste (UNNE-CONICET). C.C. 209, 3400 - Corrientes, Argentina.

2 Prof Titular de Paleobotánica, Fac. de Cs. Exact. y Nat. y Agrim. (UNNE-PRINGEPA). C.C. 128, 3400-Corrientes. 


\section{Introducción}

En este trabajo se analiza el polen de los 7 géneros que conforman la tribu Paullinieae Kunth emend. Radlk. (Sapindaceae). En el sistema de Radlkofer 1931-1934, la tribu consta de 2 subtribus: Paulliniinae y Thinouiinae Radlk., esta última con un género, Thinouia Triana \& Planchon.

Se estudiaron las especies que viven en Argentina, se incluyen además a Lophostigma plumosum Radlk. y Houssayanthus monogynus (Schdl.) Ferrucci, ambas especies no registradas para nuestro país. Para el resto de las especies analizadas en algunos casos se ha usado material procedente de países limítrofes por la calidad del material. A continuación se enumeran los géneros con el número de especies aquí tratadas: Cardiospermum L., 4 spp.; Houssayanthus Hunz., 2 spp.; Lophostigma Radlk., I sp.; Paullinia L., 3 spp.; Serjania Miller, 16 spp.; Urvillea Kunth, 4 spp. y Thinouia, 1 sp.

El objetivo principal de este trabajo es aportar datos sobre la morfología del polen, que permitan interpretar las relaciones intergenéricas y la posible tendencia evolutiva de la tribu.

Entre los antecedentes bibliográficos sobre el polen de los géneros aquí tratados se pueden mencionar trabajos de carácter morfológico, donde no se evalúa la variabilidad del polen en relación a la taxonomía de la familia, como los de Van Campo (1958), Erdtman (1966), Barros (1969), Melhem \& Campos (1969) y Salgado-Labouriau (1973). Entre los trabajos específicos sobre Sapindáceas, tenemos los relacionados con floras regionales, como Jos de Wang \& Chien (1956), Merville (1965), Cruz \& Melhem (1984) y Muller \& Schuller (1989). Radlkofer $(1897,1931)$ fue un pionero en dar valor taxonómico al polen, lo que le permitió separar dentro de la subtribu Paulliniinae a Jos géneros Serjania, Paullinia, Urvillea y Cardiospermum de Lophostigma. Para el primer grupo reconoce granos redondeados con 3 poros y 3 ángulos, deprimido-tetraédricos; mientras que para Lophostigma describe granos en forma de cilindro breve con 2 poros en cada extremo, sin mencionar la presencia de las ectoaperturas. AcevedoRodríguez (en prensa) realiza la revisión de Lophostigma donde incluye datos de polen. Merece un comentario especial el trabajo de Muller \& 
Leenhouts (1976) porque relacionan los distintos tipos de polen de la familia con la taxonomía, estudio que les permite presentar la tendencia evolutiva de cada una de las tribus.

\section{Material y métodos}

Las muestras se obtuvieron de ejemplares del herbario del Instituto de Botánica del Nordeste, Corrientes (CTES). En los casos excepcionales en que se utilizó material de otras instituciones se indica la sigla correspondiente.

Los granos de polen se prepararon utilizando la técnica de acetólisis o acetólisis-clorinación (Erdtman, 1966), se montaron en gelatina glicerinada, y se encuentran depositados en la Palinoteca de la UNNE (PAL-CTES).

Para las mediciones se usó un microscopio óptico Wild M 20. Para el análisis de la arquitectura de la pared se utilizaron fotomicrografías tomadas con un microscopio electrónico de barrido, Jeol JSM-25 SII del servicio de microscopía de la Facultad de Odontología de la Universidad de Buenos Aires; se utilizaron granos acetolizados, montados en película fotográfica y metalizados con oro.

Se estudió el polen de 2 a 6 ejemplares de cada especie a excepción de Lophostigma plumosum. Los parámetros eje polar (P) y eje ecuatorial (E) se midieron en la vista ecuatorial de 25 granos para cada una de las muestras. En la vista polar, en igual número de granos se midió el diámetro Em (Van Campo 1957: 667, fig. 3), distancia entre el ángulo apertural y el punto medio del lado opuesto, diámetro siempre ligeramente menor que el diámetro ecuatorial en vista polar. Se tomaron otras medidas, en menor número de granos, como el espesor de la exina, diámetro de aberturas, ancho de muros, tamaños de lúmenes, etc. En los parámetros donde se consignan 3 valores éstos corresponden a la medida mínima, al promedio entre paréntesis y a la medida máxima obtenida; si sólo se indica un valor éste corresponde al promedio; las medidas están expresadas en micras. Para determinar el tamaño de los granos de polen se siguió el criterio de Erdtman (1966). 
Los géneros se presentan en el texto segín la tendencia evolutiva propuesta en este trabajo.

Para la endoapertura de los géneros Serjania, Houssayanthus, Urvillea, Cardiospermum y Paullinia se indican detalles del canal del poro como los siguientes: depósito de nexina, profundidad y diámetro basal del mismo. Se define como canal del poro la endoapertura comprendida entre el límite extern o de la sexina y el lugar en que se interrumpe la nexina (Pokrovskaya \& al. 1950, dato tomado de Kremp, pág. 123).

La terminología adoptada es básicamente la de Erdtman (1966), consultándose además Kremp (1965).

Los representantes de la tribu son monoicos, presentan flores hermafroditas funcionalmente pistiladas y flores estaminadas. El polen aquí estudiado fue tomado de flores estaminadas, donde la dehiscencia es perfecta y el polen queda completamente expuesto. En L. plumosum se estudió además el polen de las flores hermafroditas. En éstas últimas las anteras muestran una línea de dehiscencia con bordes inflexos y el polen queda retenido en su interior. Se incluyó el análisis de estos granos debido a que contamos con muy escaso material proveniente de flores estaminadas. Sin embargo no es aconsejable utilizar el polen de las flores hermafroditas, ya que se observa una gran variabilidad en el tamaño de los granos y un elevado número están deformados. Por otra parte, en polen no acetolizado, el colorante carmín-glicerina colorea los granos con distinta intensidad, predominando los poco coloreados hasta incoloros. En C. grandiflorum Sw. se coloreó con azul de algodón material fresco de polen estaminodial. Se observó variación en el tamaño y en la coloración de los granos, y en los aparentemente normales el citoplasma se presenta siempre contraído. Ham (1990: 89) sintetiza observaciones realizadas por diferentes autores sobre este tema.

\section{Material estudiado}

Cardiospermum corindum L. ARGENTINA. Formosa, Matacos, Establecimiento de los Nacil. $20 \mathrm{~km}$ al $\mathrm{N}$ de Ing. G. N Juárez sobre la ruta 83, Arenas 2293, PALCTES 3097: Patiño, ruta 81, 3 km NW de J.C Bazán, 3 Pozos, Schinini \& al. 24236. PAL-CTES 1931: Salta, Metán, 14 km W-NW de El Tunal, Krapovickas \& al. 35708. PAL-CTES 2287. 
C. grandiflorum Sw. ARGENTINA. Corrientes, San Miguel $16 \mathrm{~km}$ NE Loreto, Cáceres \& al. 315, PAL-CTES 1839; Misiones, San Pedro, ruta 14, 15 km SW del desvío a San Pedro, Ferrucci \& al. 370, PAL-CTES 3101.

C. halicacabum L. var. halicacabum. BRASIL. Rio de Janeiro, estrada do Grumari, Mautone \& al. 521. PAL-CTES 2286. PARAGUAY. Nueva Asunción, Schinini 14810, PAL-CTES 3356.

C. halicacabum var. microcarpum (Kunth) Blume. ARGENTINA. Corrientes. Ituzaingó, ruta 39, $13 \mathrm{~km} \mathrm{~S}$ de ruta 12, Schinini \& al. 11375, PAL-CTES 1934; Misiones, San Ignacio, Teyucuaré, Montes 15140, PAL-CTES 3099.

C. pterocarpum Radlk. PARAGUAY. Amambay, $7 \mathrm{~km} \mathrm{~N}$ de ruta 5, Parque Nacional Cerro Corá, Ferrucci \& al. 700, PAL-CTES 3159; In regione cursus superioris fluminis Apa, Hassler 8473 (G), PAL-CTES 1935.

Houssayanthus incanus (Radlk.) Ferrucci ARGENTINA. Corrientes, Empedrado, Ea. "Las Tres Marías". Ferrucci 102, PAL-CTES 1926. PARAGUAY. Cordillera, río Salado camino de Limpio a Emboscada, Arbo \& al. 2635, PAL-CTES 3139.

H. monogynus (Schdl.) Ferrucci. PARAGUAY. Central, Itá Enramada, Ferrucci \& al. 169, PAL-CTES 3096; Paraguarí, ruta 1 y río Tebicuary, Ferrucci \& al. 177. PAL-CTES 3098.

Lophostigma plumosum Radlk. BOLIVIA. Chiquitos, O. Kuntze (M. Holotipo), PAL-CTES 1932 (polen de flor hermalrodita) - 1933 (polen de flor estaminada).

Paullinia elegans Cambess. ARGENTINA. Corrientes, Escuela de Agricultura, Schinini 12453, PAL-CTES 1923; Monte Caseros, $8 \mathrm{~km}$ S de Labougle, costa río Uruguay, Schinini \& al. 17593, PAL-CTES 3357.

P. meliaefolia A. L. Juss. ARGENTINA. Misiones, Leandro N. Alem. Picada Sueca, Maruñak 22, PAL-CTES 1924: Oberá, Campo Viera. Cruce rutas 6 y 14, Vanni \& al. 539, PAL-CTES 3109.

P. pinnala L. ARGENTINA. Corrientes, Pire 42, PAL-CTES 3110; San Cosme. Costa Toledo. Krapovickas \& al 11334, PAL-CTES 3151: Chaco, $1^{\circ}$ de Mayo. Campo Antequera, Schul7. 2260. PAL-CTES 1925.

Serjania araquei Barkley ARGENTINA. Jujuy, Capital, Lagunas de Yala, Cabrera \& al. 17489. PAL-CTES 3088; Santa Bárbara. Subida al Centinela, Rotman 941, PAL-CTES 2327, Valle Grande, Valle Colorado, Fabris 3577. PAL-CTES 3345 BOLIVIA. Chuquisaca, Tomina, Padilla $21 \mathrm{kms}$ hacia Monteagudo, Beck 6294, PALCTES 3161.

S. areolata Radlk. BOLIVIA. Tarija, Arce, pasando el puente Agua Blanca. río Bermejo (ruta Panamericana), Cuezzo \& al. 4020 (LIL), PAL-CTES 3334; Gran Chaco, Ipa, $30 \mathrm{~km} \mathrm{~N}$ de Villa Montes, Quebrada de Thainguate. Krapovickas \& al. 19476, PAL-CTES 2317-3152.

S. caracasana (Jacq.) Willd. ARGENTINA. Corrientes, San Miguel, $12 \mathrm{~km} \mathrm{NE}$ de San Miguel, Ea. Curuzú Laurel, Schınini \& al. 9360, PAL-CTES 1856; Formosa, Laishí, Colonia Yatai, Zona Velaz. Schulz 18326, PAL-CTES 3103, Salta, Caldera. ruta $9,38 \mathrm{~km} \mathrm{~N}$ de Salta. Vanni \& al. 492, PAL-CTES 3337; Gral. J. de San Martín. Schulz 5187. PAL-CTES 3142. 
S. confertiflora Radlk. ARGENTINA. Jujuy, Santa Bárbara, Aguas Calientes, Cabrera \& al. 31408, PAL-CTES 3089. BOLIVIA. Santa Cruz, Cordillera, Alto Parapetí, Michel 59, PAL-CTES 2318.

S. foveata Griseb. ARGENTINA. Salta, Caldera, El Ucumar, Schinini \& al. 22303, PAL-CTES 3085; Chicoana, Los Laureles, entrando a la Quebrada de Escoipe, Novara 5972, PAL-CTES 3162. BOLIVIA. Chuquisaca, Zudañez, Tarabuco ca. 30 kms hacia Zudañez, Beck 6234, PAL-CTES 2324-3335.

S. fuscifolia Radlk. ARGENTINA. Misiones, Parque Nacional Iguazú, Ferrucci \& al. 491, PAL-CTES 3094; San Pedro, ruta 14, Col. El Tigre, Nicora \& al. 7951, PAL-CTES 1849.

S. glabrata Kunth. ARGENTINA. Jujuy, Ledesma, camıno a Higueritas, Cabrera \& al. 32227, PAL-CTES 3160; Parque Nacional Calilegua, Iudica \& al. 278, PAL-CTES 3087; Misiones, San Pedro, ruta 17, $59 \mathrm{~km} \mathrm{~W}$ de Bernardo de Irigoyen, Ferrucci \& al. 369, PAL-CTES 1854; Salta, Gral M. M. de Güemes, Ayo. Saladillo. ruta 34, Krapovickas \& al. 17423, PAL-CTES 2292. BRASIL. Mato Grosso do Sul, Antonio João, 3-6 km O, Hatschbach \& al 49065, PAL-CTES 3106. PARAGUAY Cordillera, Tobaty, Schinini 10905, PAL-CTES 2291-3146.

S. glutinosa Radlk. ARGENTINA Misiones, Cataratas del Iguazú, Ferraro 2431, PAL-CTES 1853. BOLIVIA. Santa Cruz, Sandoval, San Matías, Krapovickas $\&$ al. 36172, PAL-CTES 3147. PARAGUAY. Central, Yaguarón, Cerro Curupayty, a $6 \mathrm{kms}$ del pueblo, Arenas 1 198. PAL-CTES 3108.

S. hebecarpa Benth. ARGENTINA. Corrientes, Santo Tomé, Ea. Timbó, Schinini \& al. 23780, PAL-CTES 1851; Misiones, Candelaria, Bonpland, Pedersen 13663. PAL-CTES 1852.

S. herteri Ferrucci ARGENTINA. Corrientes, $8 \mathrm{~km} \mathrm{~N}$ de Monte Caseros, Ayo. E1 Scibo, Cáceres \& al 288, PAL-CTES 1850-3339; Entre Ríos, Concepción del Uruguay, La Salamanca, Ayo. Itapé, Burkart \& al. 23032, PAL-CTES 3105: La Salamanca, Nicora 3211 (SI), PAL-CTES 3143.

S. laruotteana Cambess. ARGENTINA. Corrientes, Ituzaingó, Desembocadura del Ayo. Garapé en el río Paraná, $45 \mathrm{~km}$ al E de Ituzaingó, Schinini \& al. 11158 , PAL-CTES 1857-2328; Misiones, Gral. M. Belgrano, borde de la ruta SW B. de Irigoyen, Dos Hermanas, Eskuche 428, PAL-CTES 3095

S. marginata Casar. ARGENTINA. Formosa, Pilcomayo, Norte de Clorinda a ] km, Morel 2577 (LIL), PAL-CTES 1855: Jujuy, Ledesma, Calilegua, Cabrera \& al. 31341, PAL-CTES 3107-3340.

S. meridionalis Cambess. ARGENTINA. Corrientes, $12 \mathrm{~km}$ NE de San Miguel, Ea. Toro-y, Vanni \& al. 1575, PAL-CTES 2329; Santo Tomé, Ea. Timbó, Schinini \& al. 23521, PAL-CTES 1858; Misıones, San Pedro, Monte Carlo, Schwindt 1347 , PAL-CTES 3104.

S. perulacea Radlk. ARGENTINA. Corrientes, Capital, Perichón, Schinini \& al 6880, PAL-CTES 1848; Santo Tomé, Ea. Timbó, Schinini \& al. 23521, PAL-CTES 1858: Misiones, San Pedro, Monte Carlo, Schwindt 1347, PAL-CTES 3104. 
S. sufferruginea Radlk. ARGENTINA. Jujuy, Santa Bárbara, Abra de los Morteros, Cabrera \& al. 21718 (LP), PAL-CTES 3084. BOLIVIA. Chuquisaca, Tomina, Padilla 14 kms hacia Monteagudo, 2170 m, Beck 6287, PAL-CTES 2326-3332.

S. tripleuria Ferrucci. BOLIVIA. Tarija, Gran Chaco, Strasse Palos BlancosVillamontes, Gerold 298, PAL-CTES 3153; O'Connor, 35 km E de Entre Ríos, Tacuarenda, Krapovickas \& al. 39082, PAL-CTES 2325.

Thinouia mucronata Radlk. ARGENTINA. Misiones, Cainguás, ruta 14 km 252, Schwindt 3087, PAL-CTES 3102; San Javier, Tres Bocas. Schwartz 4086, PAL-CTES 1928. PARAGUAY. San Pedro, Villa Primavera, Woolston 784, PAL-CTES 3353.

Urvillea chacoensis Hunz. ARGENTINA. Chaco, Mayor L. J. Fontana. Enrique Urién, Schulz 2265, PAL-CTES 1838; Jujuy, 2 km S de Palpalá, Krapovickas \& al 30686, PAL-CTES 3092; Salta, Capital, El Carril, Legname 441. PAL-CTES 3338: Metán, Esteco, Krapovickas \& al. 27995, PAL-CTES 3140.

U. laevis Radlk. BOLIVIA. Chuquisaca, H. Siles, Monteagudo ca. $65 \mathrm{kms}$ hacia Camiri, Beck 6411, PAL-CTES 3342. BRASIL. Paraná, Cerro Azul, Mato Preto. Hatschbach 33868, PAL-CTES 3333.

U. ulmacea Kunth. ARGENTINA. Misiones, ruta $12,34 \mathrm{~km}$ SE de Puerto Iguazú, Ferrucci \& al. 478, PAL-CTES 1922; ruta 12, 34 km SE Puerto Iguazú, Ferrucci \& al. 481, PAL-CTES 3091; Salta, Anta, Parque Nacional El Rey, Obregozo 859, PAL-CTES 3330.

U. uniloba Radlk. ARGENTINA. Corrientes, Monte Caseros, $13 \mathrm{~km} \mathrm{E} \mathrm{de}$ Mocoretá, Tressens \& al. 2469. PAL-CTES 3331; Santo Tomé, Ea. Timbó, costa río Uruguay, 26 km SE de Colonia Garabí, Ahumada \& al. 4115, PAL-CTES 1921; Entre Ríos, Concordia, San Carlos, Martínez Crovetto \& al. 4309, PAL-CTES 3150.

\section{Resultados}

\section{Descripción de los granos}

\section{Tipo A - Thinouia}

\section{T. mucronata (Fig. 1, A-B)}

Granos isopolares, tricolporados, pequeños o medianos, radiosimétricos, subesferoidales a oblato-esferoidales. Amb subtriangular, ángulaperturado, lados levemente convexos o subrectos. Poros circulares o lalongados, colpos largos. Exina de $0,7 \mu \mathrm{m}$ de espesor en el ecuador gradualmente engrosada hacia los polos donde tiene entre 1,4-2,1 $\mu \mathrm{m}$. Sexina tectada estriada con escasas nanoperforaciones. Membranas aperturales ruguladas.

Medidas: $\mathrm{P}=15,7(19,7)$ 27,3; $\mathrm{E}=18$ (23) 27,3; $\mathrm{P} / \mathrm{E}=0,82(0,85) 0,89$; $\mathrm{Em}=18$ (23) 28,7. Colpo. Indice de apocolpio $=0,10-0,50$; ancho= $1(2,28)$ 6. Poro $=3(2,6) 5 \times 3,5(4,5) 5$. 
Obs. I. Cruz \& Melhem (1984) estudiaron el polen de T. ventricosa Radlk., especie que presenta granos de mayor tamaño, diferencia que también se aprecia en los poros y colpos. Para el estudio de este material utilizaron sólo MO razón por la cual no indican detalles de membranas aperturales ni presencia de nanoperforaciones.

Obs. II. En el material examinado se ha observado un bajo porcentaje de granos tetracolporados.

\section{Tipo B - Lophostigma}

\section{L. plumosum (Fig. 1, C-F)}

Granos isopolares o subisopolares, trisincolporados, heterocolpados, dicolpo-diorados, mono-colpados (dos colpos diorados y un colpo simple); medianos; radiosimétricos o asimétricos; prolatos o prolato-esferoidales. Amb circular-trilobulado. Colpos anchos en la zona ecuatorial $(2,5 \mu \mathrm{m})$, angostos en los polos. Poros lalongados, circulares o lolongados situados en el área polar. Exina de $1,8 \mu \mathrm{m}$ de espesor, sexina de $0,5 \mu \mathrm{m}$ y nexina de $1,3 \mu \mathrm{m}$; las endo- y ectoaperturas con engrosamientos de nexina o costillas de 1,5-2 $\mu \mathrm{m}$ de espesor. Sexina tectada perforada estriada, con perforaciones pequeñas, de 0,3-0,5 $\mu \mathrm{m}$ dıám., crestas y estrías de 0,3-0,7 $\mu \mathrm{m}$ de ancho. Membranas aperturales irregularmente gemadas, gemas brillantes con el MO, de 0,5-2 $\mu$ m diám.

Medidas: Flor estaminada. $\mathrm{P}=29(35,4) 41,5 ; \mathrm{E}=19,9(24,4) 29,8$; $\mathrm{P} / \mathrm{E}=1,1(1,4) 1,75 ; \mathrm{Em}=18,5(24,4) 28,6$. Colpo. Ancho=1 (2) 3. Poro= $2,5(3,7) 4,5 \times 3,5(4) 5$.

Flor hermafrodita. $\mathrm{P}=27,3(32,6) 39 ; \mathrm{E}=19,9(26) 34,6 ; \mathrm{P} / \mathrm{E}=0,85$ $(1,26) 1,67 ; \mathrm{Em}=24(28,3) 31,8$. Colpo. Ancho $=2(3,1) 3,5$. Poro $=3(3,5)$ $4 \times 3(3,6) 4$.

Fig. 1. Thinouia mucronata. A, vista ecuatorial (Schwartz 4086); B, vista polar (Schwindt 3087). Lophostigma plumosum. C, detalle del sincolpo mostrando uno de los poros; D. vista ecuatorial, mostrando el colpo simple; E, vista ecuatorial, mostrando dos de los colpos diorados: F. detalle de la exina - polen de flor hermafrodita (Kuntze s.n.). 

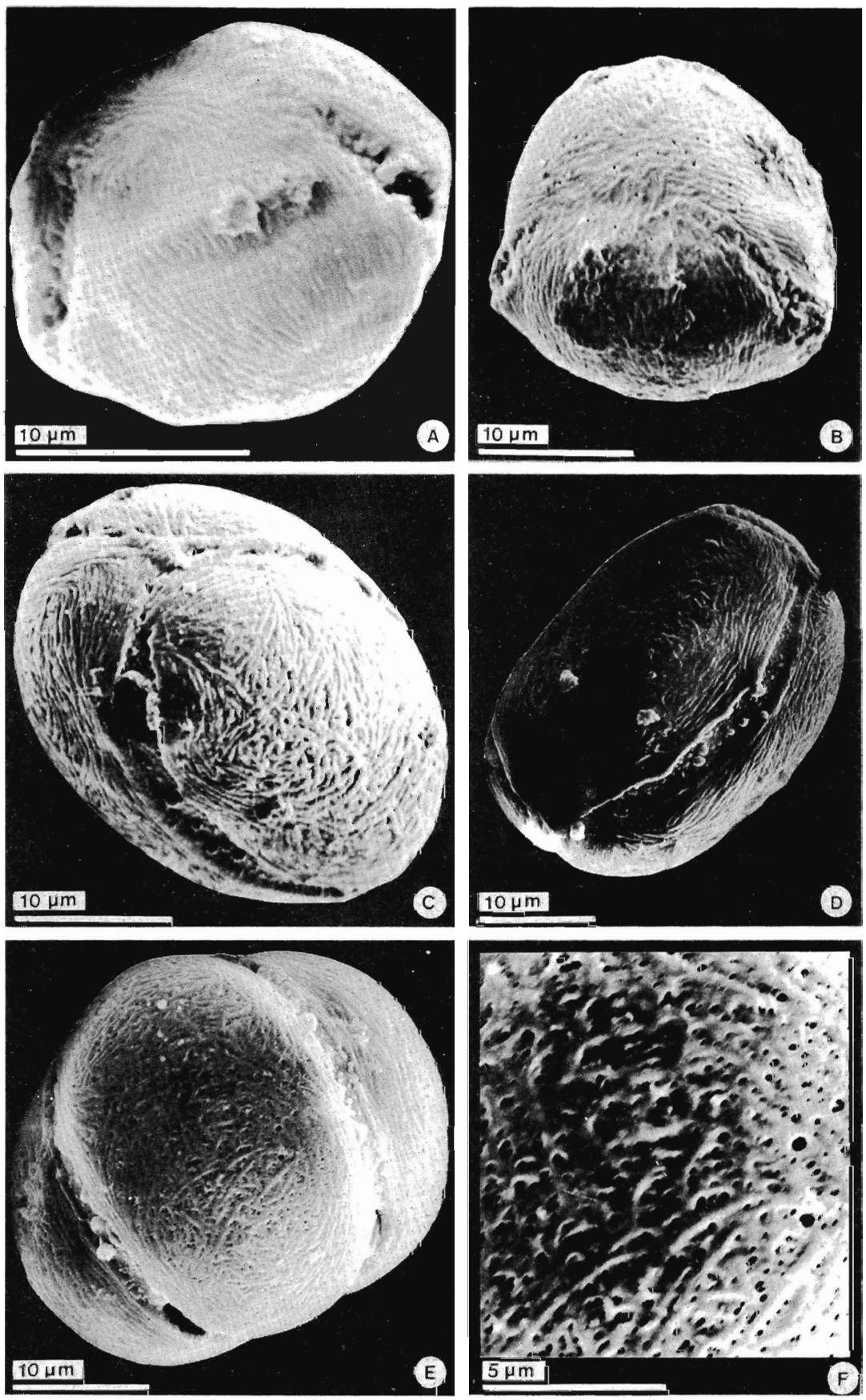
Obs. Se encontraron las siguientes diferencias respecto a la forma: en las flores estaminadas sobre 75 granos medidos la mayoría son prolatos y sólo un $6 \%$ son subesferoidal-subprolatos; mientras que en las flores hermafroditas sobre 51 granos, el $67 \%$ son subesferoidal-subprolatos, el $19 \%$ son prolatos, el $12 \%$ son prolato-esferoidales y el $2 \%$ son subesferoidal-suboblatos.

En ambos tipos de flores los granos pueden ser simétricos, o asimétricos con los sincolpos algo desplazados respecto a los polos.

En un $10 \%$ de los granos los colpos no llegan a unirse en los polos. Excepcionalmente hay granos con 2 colpos-diorados y 1 colpo con un poro en el ecuador.

Radlkofer $(1897,1931)$ describe el polen como brevemente cilíndrico, elipsoidal, con 2 pares de poros en una línea que circunda al grano próxima a los polos. Muller \& Leenhouts (1976) lo interpretaron como peroblato, con 2 poros en el ecuador. Estos autores no tuvieron acceso al material, sólo se basaron en las observaciones realizadas por Radlkofer. Nuestros resultados concuerdan en líneas generales con lo señalado por Acevedo-Rodríguez (en prensa).

\section{Tipo C - Serjania, Houssayanthus, Urvillea y Cardiospermum}

Los granos estudiados de estos géneros son: heteropolares (el polo proximal plano, cóncavo o convexo, el polo distal siempre convexo), hemitrisincolporados (ectoaperturas unidas en el polo proximal, Muller \& Leenhouts 1976: 410), medianos, radiosimétricos, peroblatos u oblatos. Amb triangular, ángulaperturado, lados rectos, convexos o cóncavos.

En la mayoría de las muestras se observa un bajo porcentaje de granos hemitetrasincolporados, sólo cuando este porcentaje es significativo se hace constar en la descripción de la especie.

Las ectoaperturas pueden ser anchas (1-2 $\mu \mathrm{m})$, con membranas aperturales expuestas, o lineares, o sólo indicadas por diferencia de escultura (colpoides). En algunas especies ellas sobrepasan hacia el polo distal hasta 1/3 de la superficie del grano desde el ecuador.

La endoapertura presenta normalmente canal del poro, el que generalmente está revestido por un depósito granular de nexina (Muller \& 
Leenhouts, 1976), éste puede ser desde abundante a nulo. Exteriormente el poro puede estar abierto o cubierto total o parcialmente por la sexina, en algunas especies las endoaperturas son protrudentes.

La exina tectada presenta las siguientes variantes: psilada o rugulada perforada, foveolada, microrreticulada o reticulada perforada.

No es posible separar los géneros sobre la base de caracteres palinológicos, sin embargo los caracteres de estructura y escultura permiten reconocer tres grupos.

GRUPO I: Granos tectados, parcial (el polo distal imperforado) o totalmente perforados, psilados a rugulados. Perforaciones de 0,2-0,3 $\mu \mathrm{m}$, en algunas especies además perforaciones de hasta $1 \mu \mathrm{m}$.

Houssayanthus incanus (Fig. 2, C-D)

Granos peroblato-oblatos u oblatos. Exina de 1,4 $\mu \mathrm{m}$ de espesor. Sexina parcial o totalmente perforada, el polo distal por lo común carece de perforaciones, y el polo proximal además de perforaciones puede presentar fósulas; generalmente plegada sobre los poros. Colpos ensanchados en el polo determinando una zona triangular con membrana apertural rugulada. Canal del poro con abundante depósito de nexina.

Medidas: $\mathrm{P}=13,2(17) 21,6 ; \mathrm{E}=28,2(32,6) 38 ; \mathrm{P} / \mathrm{E}=0,5(0,53) 0,56$; $\mathrm{Em}=25(29) 35,2$. Canal del poro= $2,1(2,7) 2,8 \times 2,1(2,7) 2,8$.

\section{H. monogynus}

Granos oblatos. Fxina de $1 \mu \mathrm{m}$ de espesor. Sexina totalmente perforada, rugulada, puede presentar fósulas en el polo proximal; generalmente plegada sobre los poros. Colpos ensanchados en el polo determinando una zona triangular con membrana apertural granulada. Canal del poro con escaso depósito de nexina.

Medidas: $\mathrm{P}=14$ (19) 24,9; $\mathrm{E}=24,9(33,2) 40,6 ; \mathrm{P} / \mathrm{E}=0,57 ; \mathrm{Em}=27,9$ $(31,2) 33,7$. Canal del poro $=1,4(2,5) 3,5 \times 2,8$ (3) 4,2.

Serjania areolata (Fig. 2, E-F)

Granos oblatos. Exina 1-1,2 $\mu \mathrm{m}$ de espesor. Polen variable, con sexina psilada escasamente perforada, o rugulada con nanogránulos y verrugas; a veces parcialmente plegada sobre los poros. Colpos lineares o reducidos a colpoides. Poros desplazados hacia el polo proximal y con los 
bordes regulares o irregulares. Canal del poro con escaso depósito de nexina.

Medidas: $\mathrm{P}=14,9$ (23) 30,7; $\mathrm{E}=33,2(43,6) 55,6 ; \mathrm{P} / \mathrm{E}=0,52 ; \mathrm{Em}=$ $33,2(40,2) 51.4$. Canal del poro $=2, I(3,3) 4,2 \times 2,1(4,4) 7$.

\section{S. caracasana}

Granos oblatos. Exina de 1,4 $\mu \mathrm{m}$ de espesor. Sexina totalmente perforada, levemente rugulada; parcialmente plegada sobre los poros, colpos lineares que a veces sobrepasan el polo distal hasta 5 um desde el ecuador. Canal del poro con abundante depósito de nexina.

Medidas: $\mathrm{P}=18(22,7)$ 27,6; $\mathrm{E}=31.2(37,9)$ 43,2; $\mathrm{P} / \mathrm{E}=0,59 ; \mathrm{Em}=$ $28,4(33,9) 38$. Canal del poro= 2,1 (2,8) 3,5 x 3,5 (4,5) 5,6.

Obs. Cruz \& Melhem (1984) describen estos granos basándose en observaciones hechas con MO y MEB. Las dimensiones de los parámetros por ellas señalados son ligeramente mayores a los aquí indicados.

\section{S. confertiflora}

Granos peroblatos u oblatos. Exina de 0,7-1 $\mu \mathrm{m}$ de espesor. Sexina totalmente perforada, levemente rugulada, perforaciones de hasta $0,5 \mu \mathrm{m}$ en el polo proximal; raro plegada sobre los poros. Colpos de 0,8-1 $\mu \mathrm{m}$ de ancho, membrana apertural rugulada. Poros ligeramente desplazados hacia el polo proximal, con los bordes irregulares. Canal del poro con escaso depósito de nexina.

Medidas: $\mathrm{P}=10,7(17,3) 22,4 ; \mathrm{E}=29(36,9) 44,8 ; \mathrm{P} / \mathrm{E}=0,42(0,47)$ 0,53; $\mathrm{Em}=27,9$ (33) 38. Canal del poro $=2,8(3,3) 3,5 \times 3,5(3,6) 5.6$.

\section{S. foveata}

Granos perublatos u oblatos. Exina de 1,5 $\mu \mathrm{m}$ de espesor. Sexina parcial o totalmente perforada, rugulada; por lo común plegada sobre los poros. Colpos de hasta I $\mu \mathrm{m}$ de ancho, membrana apertural rugulada y escasamente perforada. Canal del poro con abundante depúsito de nexina.

Fig. 2 Serjania glabrata. A. vista polar distal (Krapovickas \& al 17423): B. vista polar proximal (Ferrucci \& al. 369) Houssayanthus incanus C, vista polar distal, D, detalle de polo proximal (Ferrucci 102) Serjania areolata. E, vista polar distal, F, detalle de polo proximal (Krapovickas \& al. 19476). 

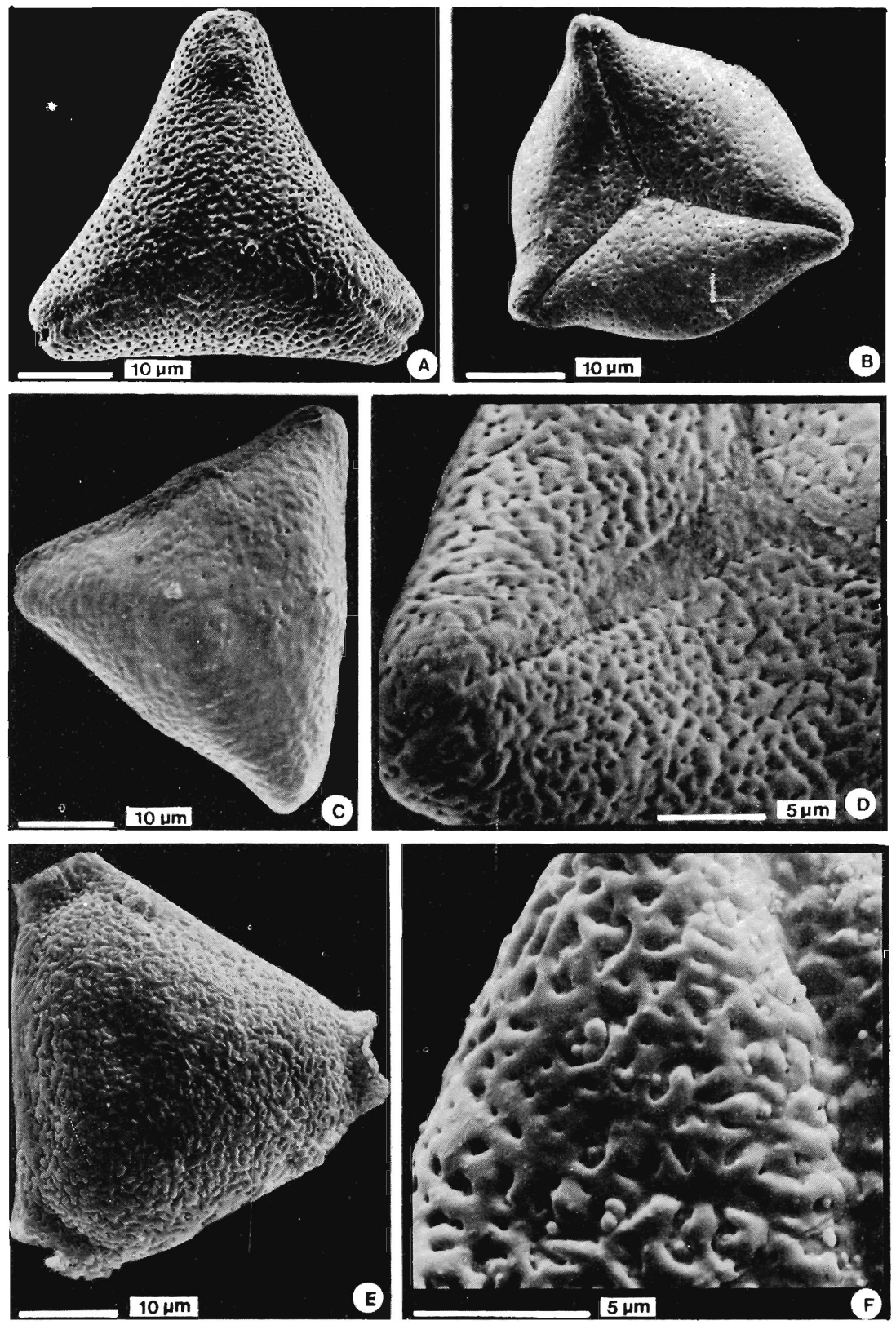
Medidas: $\mathrm{P}=11,6(17,2) 26,5 ; \mathrm{E}=26,5(31,5) 36,5 ; \mathrm{P} / \mathrm{E}=0,49(0,54)$ 0,$6 ; \mathrm{Em}=24(27,8) 31$. Canal del poro= 2,1 (2,5) $2,8 \times 2,1$ (3) 3,5 .

Obs. En la muestra correspondiente al ejemplar Beck 6234 se observaron granos con la sexina parcial y totalmente perforada.

S. fuscifolia

Granos oblatos. Exina de 1,5 $\mu \mathrm{m}$ de espesor. Sexina parcialmente perforada, levemente rugulada; generalmente plegada sobre los poros. Colpos lineares. Canal del poro con abundante depósito de nexina.

Medidas: $\mathrm{P}=14,4(19,4) 26,4 ; \mathrm{E}=24(30,3) 36 ; \mathrm{P} / \mathrm{E}=0,64 ; \mathrm{Em}=22,4$ $(26,9) 31,6$. Canal del poro $=1,4(1,7) 2,1 \times 2,8(2,9) 3,5$.

S. glabrata (Fig. 2, A-B)

Granos peroblato-oblatos u oblatos. Exina de 0,7-1,4 $\mu \mathrm{m}$. Sexina totalmente perforada, desde psilada a rugulada; total o parcialmente plegada sobre los poros. Colpos lineares o anchos de 1,5 $\mu \mathrm{m}$ de ancho, con membrana rugulada, a veces los colpos no se unen en el área polar y sobrepasan el polo distal hasta $7,5 \mu \mathrm{m}$ desde los poros. Canal del poro con abundante depósito de nexina.

Medidas: $\mathrm{P}=14(22,3) 32,5 ; \mathrm{E}=34$ (43) 52,5; $\mathrm{P} / \mathrm{E}=0,5(0,51) 0,54$; $\mathrm{Em}=27$ (39) 54. Canal del poro= 2,8 (3,3) 4,5 x 2,8 (3,3) 4,5.

Obs. Barros (1969) sobre la base de estudios con MO, interpreta estos granos como isopolares o subisopolares; respecto al tamaño sus medidas son menores, a excepción del espesor de la exina que es poco mayor.

S. hebecarpa

Granos oblatos. Exina de $1,4 \mu \mathrm{m}$ de espesor en el polo proximal y $0,7 \mu \mathrm{m}$ en el polo distal. Sexina parcialmente perforada, levemente rugulada; parcialme:nte plegada sobre los poros. Colpos lineares ensanchados en el polo determinando una zona triangular con membrana apertural rugulada. Canal del poro con abundante depósito de nexina.

Medidas: $\mathrm{P}=16,8(23) 32,4 ; \mathrm{E}=31,2(38,8) 46,8 ; \mathrm{Em}=30,4(33,5)$ 36,8. Canal del poro $=2,8(3,2) 3,5 \times 3,5$ (5) 7 .

S. herteri

Granos peroblatos u oblatos. Exina de 1,4 $\mu \mathrm{m}$ de espesor. Sexina totalmente perforada, levemente rugulada; no se pliega sobre los poros. 
Colpos lineares, de $0,7 \mu \mathrm{m}$ de ancho, ensanchados en el polo determinando una zona triangular con membrana apertural rugulada. Poros levemente protrudentes. Canal del poro con abundante depósito de nexina.

Medidas: $\mathrm{P}=9,6(17,8) 28,2 ; \mathrm{E}=26,4(33,2) 39,8 ; \mathrm{P} / \mathrm{E}=0,45(0,53)$ 0,$6 ; \mathrm{Em}=24(29,3) 34,5$. Canal del poro= $2,8(3,3) 4,2 \times 2,2(2,8) 3,5$.

S. laruotteana

Granos peroblatos u oblatos. Exina de $1 \mu \mathrm{m}$ de espesor. Sexina parcial o totalmente perforada, psilada a levemente rugulada; parcialmente plegada sobre los poros. Colpos lineares de $0,5 \mu \mathrm{m}$ de ancho. Canal del poro con escaso depósito de nexina.

Medidas: $\mathrm{P}=13,2(16,9) 23,2 ; \mathrm{E}=27,3$ (33) 37,3; $\mathrm{P} / \mathrm{E}=0,49(0,51)$ 0,53; $\mathrm{Em}=24$ (29) 34. Canal del poro= 1,4 (2) $2,8 \times 1,4$ (2) 2,8 .

Obs. Cruz \& Melhem (1984) estudiaron este material con MO, comparando sus resultados con los nuestros, se observan diferencias en las medidas de los granos y en el espesor de la exina, siempre mayores en el trabajo citado.

\section{S. meridionalis}

Granos oblatos. Exina de $1,4 \mu \mathrm{m}$ de espesor. Sexina totalmente perforada, rugulada, en el ecuador las perforaciones tienen 0,75-1 $\mu$ m diám.; plegada sobre los poros. Colpos de 1,5 $\mu \mathrm{m}$ de ancho, con membranas aperturales ruguladas y perforadas. Canal del poro con abundante depósito de nexina.

Medidas: $\mathrm{P}=12,4$ (19) 23,4; $\mathrm{E}=24,9(31,5) 36,5 ; \mathrm{P} / \mathrm{E}=0,60 ; \mathrm{Em}=$ $27,3(29,4) 31,2$. Canal del poro= $2,1(2,6) 2,8 \times 2,1(2,5) 3,5$.

\section{S. perulacea}

Granos peroblato-oblatos u oblatos. Exina de 1,4 $\mu \mathrm{m}$ de espesor. Sexina totalmente perforada, perforaciones de hasta $0,6 \mu \mathrm{m}$ diám., las más grandes en intercolpios del polo proximal, rugulada; no plegada sobre los poros. Colpos de 1-1,7 $\mu \mathrm{m}$ de ancho, con membranas aperturales ruguladas y perforadas. Canal del poro con abundante depósito de nexina.

Medidas: $\mathrm{P}=14(17,9) 24,9 ; \mathrm{E}=29,8(33,9) 40,6 ; \mathrm{P} / \mathrm{E}=0,5(0,52)$ 0,$55 ; \mathrm{Em}=27,9(31,5) 36,2$. Canal del poro $=1,4(2) 2,8 \times 2,8(3,2) 3,5$. 


\section{S. tripleuria}

Granos peroblatos o peroblato-oblatos. Exina de 1,4 $\mu \mathrm{m}$ de espesor. Sexina totalmente perforada, rugulada, generalmente plegada sobre los poros. Colpos de 2-2,5 $\mu \mathrm{m}$ de ancho, ensanchados en el polo determinando una zona triangular con membrana apertural rugulada, con escasas perforaciones. Canal del poro con escaso depósito de nexina.

Medidas: $\mathrm{v}=14(19) 25,9 ; \mathrm{E}=28,2(38,5) 48 ; \mathrm{P} / \mathrm{E}=0,49-0,50 ; \mathrm{Em}=$ $27(32,6) 38,7$. Canal del poro= $2,8(3,4) 4,1 \times 2,1(3,3) 3,5$.

GRUPO II: Granos tectados perforados, parcial o totalmente foveolados, fóveas de hasta $2 \mu \mathrm{m}$ de diám. mayor.

S. araquei (Fig. 3, A)

Granos peroblatos. Exina de 1,4 $\mu \mathrm{m}$ de espesor. Sexina foveolada sólo en el polo proximal, en algunos granos perforada; en el polo distal tectada psilada imperforada y en el ecuador con perforaciones. Sexina parcialmente plegada sobre los poros. Ectoaperturas reducidas a colpoides. Poros levemente protrudentes y desplazados hacia el polo proximal. Canal del poro con escaso depósito de nexina.

Medidas: $P=14,9(17,2) 19,9 ; E=29,8(36,4) 41,5 ; P / E=0,47 ; E m=$ 27 (32) 40,9. Canal del poro= 2, $1(2,2) 3,5 \times 2$ (3) 4,2.

S. marginata (Fig. 3, C)

Granos oblatos. Exina de 1-1,2 $\mu \mathrm{m}$ de espesor. Sexina foveolada sólo en el polo proximal, en el polo distal tectada psilada con perforaciones dispersas. Téctum de las fóveas con báculas libres. Sexina parcialmente plegada sobre los poros. Colpos de 0,8-1,1 $\mu \mathrm{m}$ de ancho, ensanchados en el polo determinando una zona triangular con membrana apertural rugulada. Canal del poro con abundante depósito de nexina.

Medidas: $\mathrm{P}=13,2(18,7) 23,2 ; \mathrm{E}=25,7(35,9) 40,6 ; \mathrm{P} / \mathrm{E}=0,52 ; \mathrm{Em}=$ $29,8(32,9) 35,4$. Canal del poro= $2,1(2,8) 3,5 \times 1,4(2,8) 4,5$.

\section{S. sufferruginea (Fig. 3, B, D)}

Granos peroblatos u oblatos. Exina de 1,5 $\mu \mathrm{m}$ de espesor. Granos variables, con sexina totalmente foveolada, o fosulada (fósulas de hasta 2,75 $\mu \mathrm{m}$ diám.) en el polo proximal y perforada en el polo distal. Sexina a veces parcialmente plegada sobre los poros. Colpos lineares, rara vez se ob- 

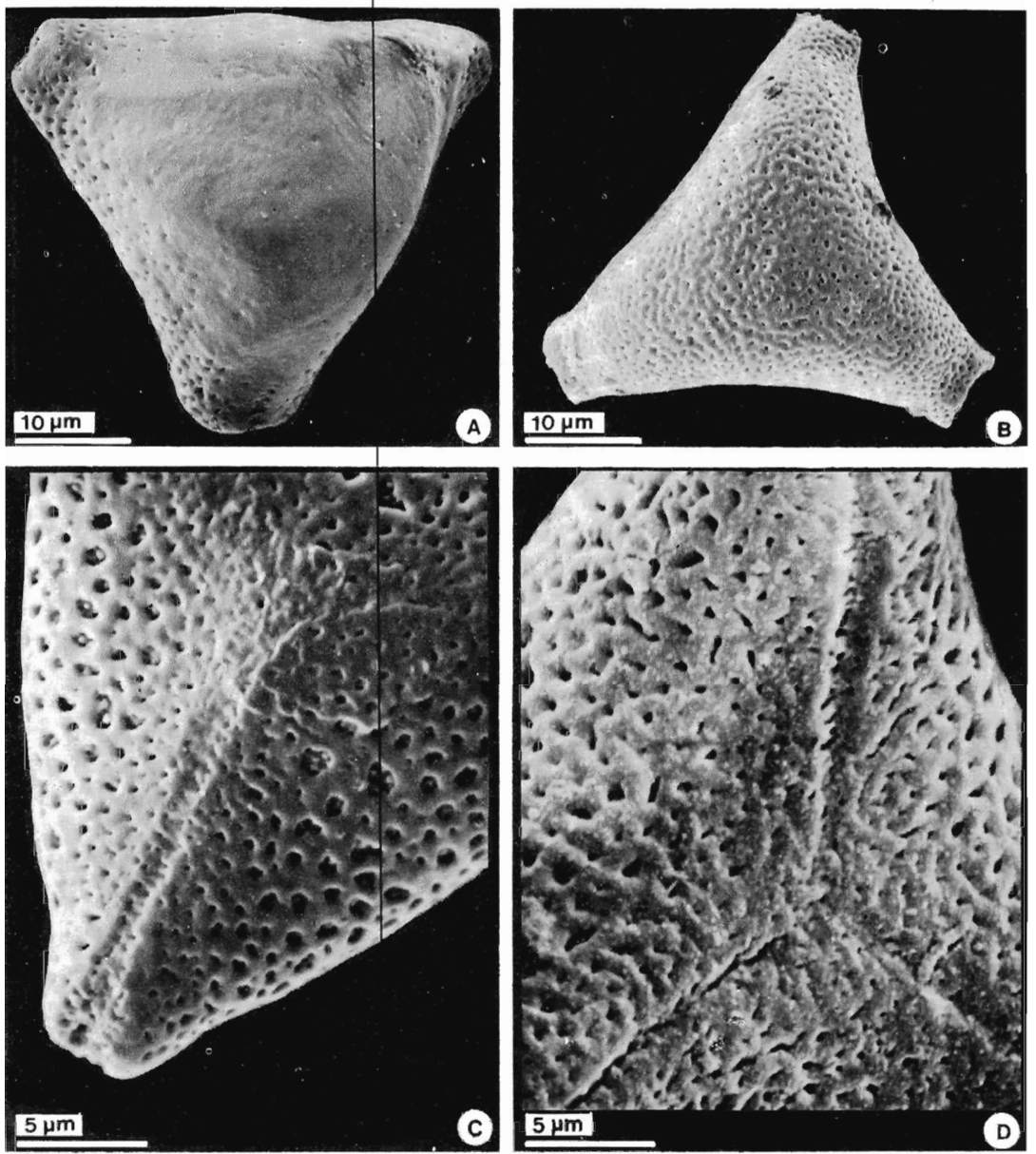

Fig. 3. Serjania araquei. A. vista polar distal (Rotman 941). S. sufferrugınea. B, vista polar distal; D, vista polar proximal (Beck 6287). S. marginata. C, detalle de polo proximal (Cabrera \& al. 3134 l).

serva la membrana apertural rugulada y perforada. Poros desplazados hacia el polo proximal. Canal del poro con escaso depósito de nexina. 
Medidas: $\mathrm{P}=14,9(20,9) 30,7 ; \mathrm{E}=36,5(44,7) 52,2 ; \mathrm{P} / \mathrm{E}=0,42(0,47)$ 0,$52 ; \mathrm{Em}=33,2(38,8) 45,9$. Canal del poro $=1,4(2) 2,8 \times 3,5(4,6) 6,3$.

GRUPO III: Granos tectados reticulados, con téctum perforado, heterobrocados.

\section{Cardiospermum corindum}

Granos peroblatos. Exina de 1,4-2 $\mu \mathrm{m}$ de espesor. Lúmenes del retículo circulares a poligonales de hasta $2 \mu \mathrm{m}$ diám., muros duplibaculados, de $\pm 1 \mu \mathrm{m}$ de ancho. Sexina generalmente no plegada sobre los poros. Colpos lineares, débilmente marcados, a veces reducidos a colpoides, éstos señalados por una banda tectada psilada, limitada a ambos lados por otra tectada perforada. Algunos granos con poros protrudentes. Canal del poro con escaso depósito de nexina.

Medidas: $\mathrm{P}=11,6(16,6) 23,2 ; \mathrm{E}=33,2(41,2) 50,6 ; \mathrm{P} / \mathrm{E}=0,40 ; \mathrm{Em}=$ $30(39,2) 43,4$. Canal del poro= $3,5(4,2) 5,6 \times 4,9(5,6) 6,3$.

\section{C. grandiflorum (Fig. 4, A)}

Granos oblatos. Exina de 1,4-2 $\mu \mathrm{m}$ de espesor. Lúmenes del retículo poligonales, de 1-3,75 $\mu \mathrm{m}$ diám., con téctum perforado, muros duplibaculados de 1-1,5 $\mu \mathrm{m}$ de ancho. Sexina plegada o parcialmente plegada sobre los poros; éstos protrudentes. Colpoides señalados por doble hilera de lúmenes pequeños o téctum perforado. Canal del poro con escaso depósito de nexina.

Medidas: $\mathrm{P}=21,5$ (33) 40; $\mathrm{E}=38$ (52) 58; $\mathrm{P} / \mathrm{E}=0,63 ; \mathrm{Em}=44,8(43,8)$ 49,5. Canal del poro=2,8 $(3,5) 5,6 \times 3(3,5) 4,2$.

Obs. I. Merville (1965), sobre la base de observaciones hechas con $\mathrm{MO}$, interpreta estos granos como triporados, subisopolares en cuanto a su forma y netamente heteropolares en cuanto a la ornamentación, señala además muros pluribaculados. En las microfotografías que ilustran ese traba-

Fig. 4. Cardiospermum grandiflorum. A, vista polar distal (Cáceres \& al. 315). Serjania glutinosa. B, detalle de polo proximal (Ferraro 2431). C. halicacabum var. halicacabum. C, polo distal; D, detalle de la exina (Mautone \& al. 521). Paullinia elegans. E, vista polar (Schinini 12453). P. pinnata. F, detalle del poro (Schulz 2260). 

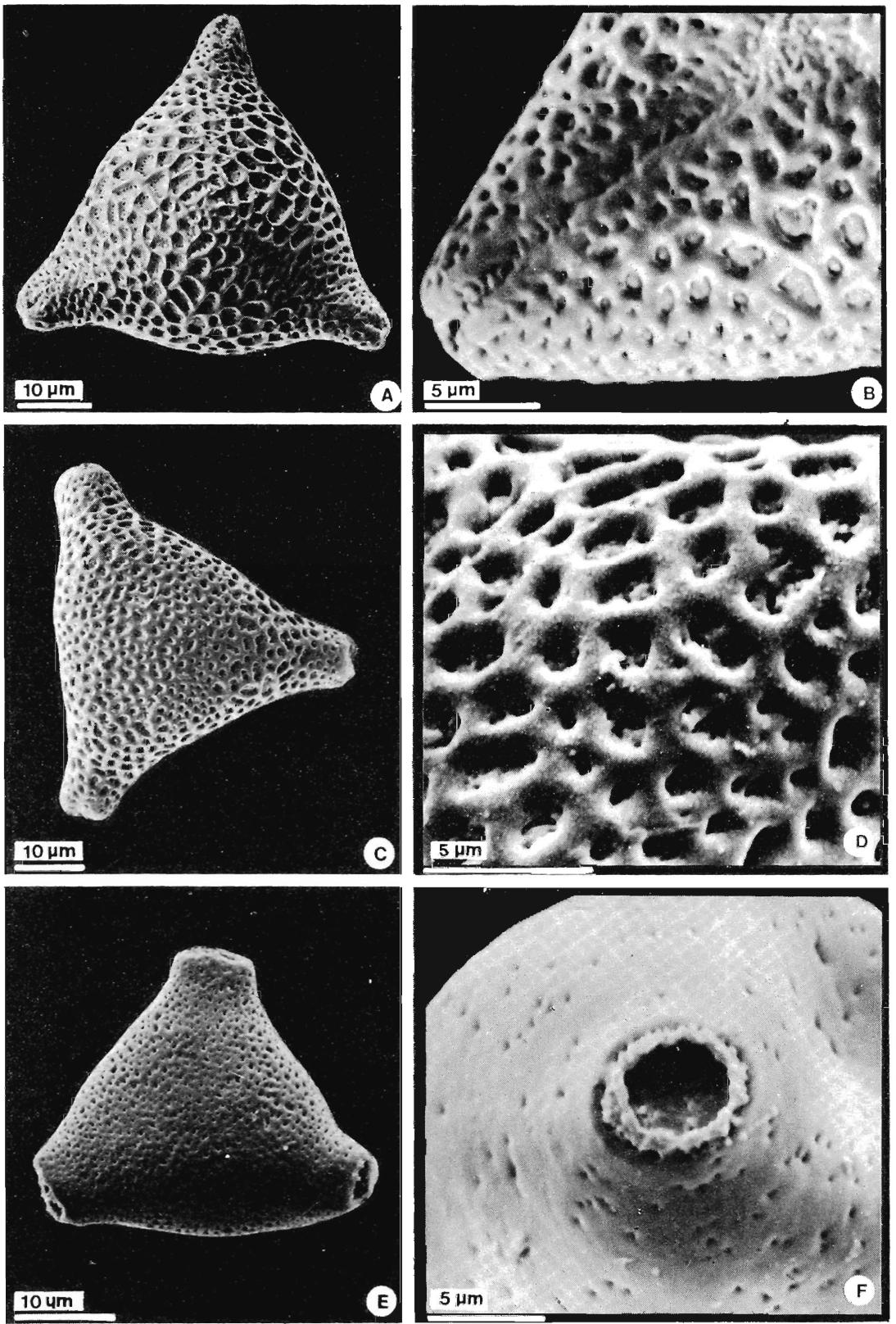
jo, se observan diferencias en el retículo que corresponderían a los colpoides (Pl.II, 16-17).

Obs. II. En el ejemplar Cáceres \& al. 315, el 25\% de los granos son triporados ( $\sin$ colpoides).

C. halicacabum (Fig, 4, C, D)

Granos peroblatos. Exina de 1,4-2 $\mu \mathrm{m}$ de espesor. Lúmenes del retículo circulares a poligonales, de 1-1,5 $\mu$ m diám., téctum de los lúmenes perforado, algunas perforaciones alcanzan hasta $1 \mu \mathrm{m}$ diám. lo que determina la reducción total del mismo en algunos lúmenes; muros multibaculados, de 1-1,2 $\mu \mathrm{m}$ de ancho. Sexina generalmente plegada sobre los poros. Colpos lineares, débilmente marcados, a veces reducidos a colpoides, señalados por una banda tectada psilada limitada a ambos lados por otra tectada perforada. Poros en la mayoría de los granos protrudentes. Canal del poro con abundante depósito de nexina.

Medidas: $\mathrm{P}=9,96(17,2) 23,2 ; \mathrm{E}=31,5(40,5) 46,4 ; \mathrm{P} / \mathrm{E}=0,42 ; \mathrm{Em}=$ $27(36,5) 46$. Canal del poro= 4,9 (6,3) 7 x 4,9 $(5,6) 6,3$.

Obs. Se presentan comentarios de trabajos realizados con MO:

Las dimensiones correspondientes a los ejes polar y ecuatorial citadas por Wang \& Chien (1956) para material del sur de China son bastante mayores que las indicadas en este trabajo, sólo se podrían homologar a las dadas por Selling (1947) para dichos parámetros.

Van Campo (1958) describe estos granos como heteropolares, triporados, breviaxiles, las dimensiones de los ejes polar y ecuatorial son mayores que las observadas en nuestro material como así también el espesor de la exina $(2,5 \mu \mathrm{m})$. La autora interpreta, con dudas, la estratificación de la exina como tectada reticulada (pl. 42, 9). En la fotomicrografía (pl. 42,1) se observan con nitidez los colpoides indicados por diferencia de escultura.

Barros (1969) señala que los muros son simplibaculados; las dimensiones de los ejes polar y ecuatorial están dentro de la franja de variación que nosotras indicamos para la especie, pero la razón $\mathrm{P} / \mathrm{E}=0,6$ (oblato) es bastante mayor que la nuestra, como así también el espesor de la exina $(\operatorname{sexina}=1,5-2 \mu \mathrm{m}$, nexina $=1,5-2 \mu \mathrm{m})$. 
Muller \& Schuller (1989) indican que los muros son multibaculados; las dimensiones de los ejes polar y ecuatorial, como así también la razón $\mathrm{P} / \mathrm{E}=0,5$, son mayores que las señaladas en este trabajo.

Estudios con MEB realizados por Muller \& Leenhouts (1976, pl. 11, D-F) ilustran ambas vistas polares y muestran un corte a nivel ecuatorial de la endoapertura parcialmente taponada con depósito nexínico.

C. pterocarpum

Granos peroblatos. Exina de 1,4 $\mu \mathrm{m}$ de espesor. Lúmenes del retículo poligonales, de hasta 1,5 $\mu \mathrm{m}$ diám., algunos son restos muy reducidos de téctum, muros de 0,3-0,7 $\mu \mathrm{m}$ de ancho. Sexina plegada sobre los poros. Colpos lineares, algunos sobrepasan hasta $1 / 3$ desde el ecuador. Canal del poro sin depósito de nexina.

Medidas: $\mathrm{P}=8,3(12,8) 15 ; \mathrm{E}=23$ (30) 34; $\mathrm{P} / \mathrm{E}=0,42 ; \mathrm{Em}=23$ (26) 30. Canal del poro $=0,7$ (1) $1,4 \times 2,7(4,5) 5,6$.

Serjania glutinosa (Fig. 4, B)

Granos peroblatos u oblatos. Exina de 1,4 $\mu \mathrm{m}$ de espesor. Sexina tectada perforada psilada en el polo distal y en el polo proximal reticulada, heterobrocada, con lúmenes de hasta $2,5 \mu \mathrm{m}$ diám. y muros de 0,5-1,5 $\mu \mathrm{m}$ de ancho, la superficie de los lúmenes está ocupada por téctum, el que presenta báculas libres y escasas perforaciones en el límite con los muros. Sexina generalmente plegada sobre los poros. Colpos lineares ensanchados en el polo determinando una pequeña zona triangular con membrana apertural rugulada. Canal del poro con abundante depósito de nexina.

Medidas: $\mathrm{P}=14,9(20,6) 28,2 ; \mathrm{E}=28(38,9) 44,8 ; \mathrm{P} / \mathrm{E}=0,48(0,52)$ 0,56; $\mathrm{Em}=31,5(35,4) 40,3$. Canal del poro=2,1 (3) 3,5 x 3,5 (5) 5,6.

Obs. Melhem \& Campo (1969) trabajaron sólo con MO, y observaron igual que nosotras diferencias en el tamaño de los lúmenes. Los valores para los ejes polar y ecuatorial, la relación P/E y el grosor de la exina $(1,9 \mu \mathrm{m})$ son ligeramente mayores que los indicados por nosotras. SalgadoLabouriau (1973) analiza el polen de Serjania basándose en el análisis de S. lethalis Cambess., S. erecta Radlk. y S. glutinosa. Describe a los poros con margen, y da un valor aproximado de 1,6 $\mu \mathrm{m}$ para el espesor de la exina. En la clave para diferenciar estas especies utiliza el diámetro ecua- 
torial, indicando un rango de variación de 36,6-38,4 $\mu \mathrm{m}$ para $S$. glutinosa, rango menor que el señalado en nuestro trabajo.

\section{Urvillea}

Granos peroblatos u oblatos. Exina de 1,4-2 $\mu \mathrm{m}$ de espesor. Granos con la estructura de la exina variable, aunque con un patrón microrreticulado común a todas las especies. Lúmenes del retículo de 0,3-1,85 $\mu \mathrm{m}$ diám., muros de 0,25-0,9 $\mu \mathrm{m}$ de ancho. Sexina a veces plegada sobre los poros. Colpos lineares, de hasta $0,90 \mu \mathrm{m}$ de ancho, a veces se ensanchan en los polos determinando una pequeña zona triangular, con membrana apertural rugulada o granulada. Canal del poro sin depósito de nexina.

\section{$U$. chacoensis}

Granos peroblatos u oblatos. A veces la sexina tectada foveolada, fóveas de hasta $1,1 \mu \mathrm{m}$, o reticulada con los lúmenes perforados en el límite con los muros.

Medidas: $\mathrm{P}=9,9$ (14) $18 ; \mathrm{E}=19,9$ (27) 30,$7 ; \mathrm{P} / \mathrm{E}=0,47(0,52) 0,57$; $E m=22(25,3) 28,2$. Canal del poro= $2,1(2,3) 2,8 \times 3,5(3,6) 4,3$.

Obs. En la muestra de $U$. chacoensis (PAL-CTES 3092) se observan granos foveolados, microrreticulados y reticulados con lúmenes perforados; estas diferencias manifiestas en el mismo ejemplar reflejan la variabilidad de la sexina.

\section{U. laevis}

Granos peroblatos u oblatos. La exina de 0,7 $\mu \mathrm{m}$ de espesor, microrretículo con lúmenes de hasta $1,3 \mu \mathrm{m}$ y muros de $0,95 \mu \mathrm{m}$ de ancho; a veces el microrretículo muy apretado; colpos lineares de hasta 0,9 $\mu \mathrm{m}$ de ancho, con membrana apertural rugulada.

Medidas: $\mathrm{P}=10$ (13) 16,6; $\mathrm{E}=21,5(26) 31,5 ; \mathrm{P} / \mathrm{E}=0,46(0,50) 0,54$; $E m=19,6(22,3) 25$. Canal del poro= $2,1(2,5) 2,8 \times 2,8(3,6) 4,9$.

\section{U. ulmacea}

Granos oblatos. El microrretículo con lúmenes de 0,4-0,8 $\mu \mathrm{m}$ y los muros son de 0,4-0,6 $\mu \mathrm{m}$ de ancho, el colpo a veces sobrepasa hasta $9 \mu \mathrm{m}$ desde el ecuador hacia la cara no apertural.

Medidas: $\mathrm{P}=14(17) 21,5 ; \mathrm{E}=26,5(32,9) 41,5 ; \mathrm{P} / \mathrm{E}=0,52 ; \mathrm{Em}=24,3$ $(28,4) 31,5$. Canal del poro $=1,4$ (2) $2,1 \times 3,5(3,8) 4,9$. 


\section{U. uniloba}

Granos oblatos. La sexina a veces foveolada, colpos lineares de hasta $0,75 \mu \mathrm{m}$ de ancho.

Medidas: $\mathrm{P}=12,4(15,7) 19 ; \mathrm{E}=23,2(29) 34 ; \mathrm{P} / \mathrm{E}=0,54 ; \mathrm{Em}=22,6$ $(26,2) 29,8$. Canal del poro $=2,1$ (3) $3,5 \times 2,8(4,3) 5,6$.

\section{Tipo D - Paullinia}

Granos isopolares o subisopolares, triporados, medianos, radiosimétricos, oblatos, raro peroblatos, de contorno biconvexo o convexo-plano o convexo-cóncavo. Amb subtriangular, ángulaperturado, lados desde levemente cóncavos o algo convexos. Exina de 1-2 $\mu$ m de espesor. Sexina tectada perforada, apenas rugulada en algunos granos, con perforaciones pequeñas de 0,2-0,3 $\mu \mathrm{m}$ diám., las que a veces alternan con otras de mayor tamaño 0,5-1,2 $\mu \mathrm{m}$. Canal del poro pequeño, revestido internamente con depósito granular de nexina, el que generalmente sobresale por fuera del poro como un anillo granular de hasta $1 \mu \mathrm{m}$ de espesor.

\section{P. elegans (Fig. 4, E)}

Granos peroblatos u oblatos. Exina de $1 \mu \mathrm{m}$ de espesor. Canal del poro con abundante depósito de nexina.

Medidas: $\mathrm{P}=9,96(16,5) 21,2 ; \mathrm{E}=23,2(30,8) 41,5 ; \mathrm{P} / \mathrm{E}=0,48(0,53)$ 0,$59 ; \mathrm{Em}=23,9(28,3) 33,7$. Canal del poro $=3(3,5) 4 \times 3(4) 5$.

P. meliaefolia

Granos oblatos. Exina de 1,5-2 $\mu \mathrm{m}$ de espesor. Canal del poro con abundante depósito de nexina.

Medidas: $\mathrm{P}=16,6(19,5) 22,4 ; \mathrm{E}=28,2(30,9) 36,5 ; \mathrm{P} / \mathrm{E}=0,63 ; \mathrm{Em}=$ $21,5(26,8) 30,9$. Canal del poro $=2(2,6) 3 \times 3(4,2) 6$.

P. pinnata (Fig. 4, F)

Granos oblatos. Exina de 1,5-2 $\mu \mathrm{m}$ de espesor. Canal del poro con abundante depósito de nexina. A veces el canal del poro ausente.

Medidas: $\mathrm{P}=16,6(20,4) 22,4 ; \mathrm{E}=31,5(34,6) 38 ; \mathrm{P} / \mathrm{E}=0,59 ; \mathrm{Em}=$ $28,5(30,3) 32,9$. Canal del poro $=1(1,3) 2 \times 7(7,5) 9$.

Obs. Erdtman (1966) describe estos granos sobre material sudafricano, sus observaciones concuerdan con las nuestras a excepción del tipo de 
apertura que interpreta como colporo. Merville (1965) señala dimorfismo en los granos en lo que se refiere a las dimensiones de los ejes polar y ecuatorial con un $20 \%$ de granos más pequeños; el espesor de la exina $(2,7$ $\mu \mathrm{m})$ es ligeramente mayor que el indicado por nosotras. Barros (1969) describe la superficie como psilada, con la sexina menos espesa que la nexina, constituida por báculas finísimas que forman un delgado retículo. Las medias de los diámetros polar y ecuatorial coinciden con las nuestras, pero la relación $\mathrm{P} / \mathrm{E}=0,5$ es menor que la señalada por nosotras. Muller \& Schuller (1989) presentan resultados que concuerdan con los nuestros, a excepción de la razón $\mathrm{P} / \mathrm{E}=0,7$ que es mayor que la aquí indicada.

\section{Discusión}

La morfología del polen de Paullinieae nos permite caracterizar a los géneros Thinouia, Lophostigma y Paullinia. Mientras que las especies de Cardiospermum, Urvillea, Serjania y Houssayanthus comparten el tipo de polen, pudiéndose sólo establecer grupos sobre la arquitectura de la pared.

Se presentan a continuación comentarios sobre los caracteres analizados y se sugiere la posible tendencia evolutiva que han seguido los mismos.

Tamaño: Si consideramos el eje de mayor longitud del grano, Thinouia mucronata presenta granos pequeños o medianos; Lophostigma, Houssayanthus, Serjania, Urvillea y 3 de las 4 especies de Cardiospermum tienen granos medianos y sólo $C$. grandiflorum posee granos medianos o grandes. La presencia de granos medianos es común a todos los géneros de la tribu, mientras los granos grandes de C. grandiflorum, estarían correlacionados con flores de mayor tamaño, lo mismo ocurre con $C$. heringeri y C. integerrimum (Ferrucci, 1993). Muller (1979) menciona una serie de trabajos, entre ellos el de Baum \& al. (1971), donde se relacionan tamaño de flor y polen.

Dentro de las Sapindáceas los granos de mayor tamaño corresponden a Paullinieae. Si consideramos el criterio de Muller (1970) quien señala que los granos de mayor tamaño, con aperturas y arquitectura de la pared especializadas implican condiciones avanzadas, podemos postular 
que la tendencia evolutiva para la tribu va desde granos pequeños a grandes. Este mismo criterio ha sido ya utilizado para interpretar la tendencia evolutiva en cuatro géneros de Nephelieae-Sapindaceae (Berg, 1978).

Walker \& Doyle (1975) señalan para angiospermas en general que este carácter es fácilmente reversible y debe entonces correlacionarse con otros caracteres del taxón para valorizarlo correctamente. En Paullinieae la tendencia aquí postulada está también sustentada por lo observado en otros caracteres como tipo de apertura y especialmente arquitectura de la pared los que se discuten más adelante.

Simetría: Todos los géneros de Paullinieae, a excepción de Lophostigma, presentan granos radiosimétricos, L. plumosum posee tanto granos simétricos como asimétricos. Para la familia se registra un antecedente de asimetría en Lepisanthes amoena (Hassk.) Leenh. donde un pequeño porcentaje de granos son sincolpado-asimétricos en una de las muestras (Muller, 1970). El estado del carácter asimétrico es difícıl de evaluar desde el punto de vista evolutivo.

Polaridad: La variación observada va desde granos isopolares en Thinouia, granos iso- o subisopolares en Lophostigma y Paullinia, a heteropolares en Serjania, Houssayanthus, Urvillea y Cardiospermum. En este último grupo en vista ecuatorial el polo distal es siempre convexo, mientras que el polo proximal puede ser plano, cóncavo o convexo, variación que puede observarse en la misma muestra. Interpretamos que en Paullinia los granos son secundariamente iso- o subisopolares, ya que se habrían originado por reducción de las ectoaperturas de los granos heteropolares.

Amb: El contorno ecuatorial en Lophostigma es subcircular-trilobado, mientras que en Thinouia y en el grupo de Serjania, Houssayanthus, Urvillea, Cardiospermum y Paullinia el ámbito es subtriangular o triangular, ángulaperturado respectivamente.

P/E: En Thinouia los granos son subesferoidales y en Lophostigma prolatos o subesferoidal-subprolatos. Serjania, Houssayanthus, Cardiospermum, Urvillea y Paullinia tienen granos peroblatos y/o oblatos con un rango de variación de 0,4-0,64; dentro de este grupo se estudiaron tres especies 
de Cardiospermum con granos netamente peroblatos, y una, C. grandiflorum, con granos oblatos $(0,63)$.

Estos géneros responden al modelo breviaxil propuesto por Van Campo (1976), cuya serie morfológica es: grano tricolporado, subesférico tricolporoidado, oblato tricolporado con frecuencia sincolpado, triporado; dirección evolutiva sustentada por el registro fósil. Este tipo de polen está ampliamente representado en la subclase Rosidae (Walker \& Doyle, 1975), a la cual pertenece Sapindaceae.

Aperturas: Este carácter permite reconocer 4 tipos de polen en Paullinieae. El tipo A - tricolporado característico de Thinouia, es básico para la tribu, como así también para la familia (Muller \& Leenhouts, 1976). A partir de este tipo se habrían diferenciado en forma independiente: el tipo B - trisincolporado, heterocolpado, dicolpo-diorados, monocolpado, exclusivo de Lophostigma, y el tipo C - hemitrisincolporado característico de Serjania, Houssayanthus, Urvillea y Cardiospermum. Por esta vía, con la reducción de las ectoaperturas, se llega al tipo D - triporado de Paullinia.

Ham (1990) propone como probable origen de Paullinieae a Cupanieidites Cookson \& Pike emend. Chmura, género fósil con sistema apertural (para)sincolporado. Este autor considera que el estado del carácter sincolporado sería primitivo, mientras que el estado colporado sería derivado, interpretándolo como una reversión. La aceptación de esta teoría implicaría desconocer la posición primitiva de Thinouia dentro de la tribu, sustentada por los caracteres macromorfológicos, palinológicos y citológicos. Si bien hasta el presente Cupanieidites, es el representante fósil con más antiguiedad dentro de la familia, Cretácico superior, queda abierto el interrogante, de si entre el gran número de tricolporados que ya aparecen en el Cretácico inferior-Albiano medio y superior, no estén presentes granos de Sapindaceae, comparables a los de Sapindáceas arbóreas actuales como por ejemplo Diplokeleha N.E.Br., Diatenopteryx Radlk., Sapindus L., Melicoccus P. Browne y Dodonaea Miller, que poseen granos tricolporados (Anzótegui \& Ferrucci, 1992). Por todo lo expuesto es muy aventurado pretender señalar como estado primitivo para la familia a los granos (para)sincolporados, oblatos y de ámbito triangular, sólo por el registro fósil de Cupanieidites. 
Arquitectura de la pared: En la tribu la estructura de la exina va desde tectada parcialmente perforada hasta parcialmente semitectada, tendencia evolutiva que concuerda con lo observado en la mayoría de angiospermas (Walker \& Doyle, 1975).

Thinouia y Lophostigma comparten la exina tectada estriada con escasas nanoperforaciones, escultura generalmente asociada a granos esferoidales o prolatos. Mientras que en los restantes géneros, Serjania, Houssayanthus, Urvillea, Cardiospermum y Paullinia, con granos breviaxiles, la estructura va desde parcialmente perforada a parcialmente semitectada, con escultura desde tectada-psilada a reticulada. La serie morfológica observada en la estructura de la exina de Paullinieae concuerda con lo citado por Muller para Lepisanthes Bl. y Harpullia Roxb. (1970, 1985).

La variabilidad en la arquitectura de la pared que presentan algunas especies de la tribu, como $U$. chacoensis se había observado ya en la familia. A veces gran parte de una serie morfológica se presenta en una sola muestra (Muller, 1970, 1971; Ham, 1977, 1989, 1990).

Para finalizar se evalúan los caracteres macromorfológicos y los datos cromosómicos resumidos en la Tabla 1, que correlacionados con el tipo de polen apoyan la tendencia evolutiva aquí propuesta.

Thinouia sería el género más primitivo de la tribu, así lo indican sus flores actinomorfas, con cáliz y corola pentámeros, las escamas de los pétalos poco desarrolladas e iguales entre sí y el disco nectarífero completo. El número cromosómico, $2 n=28$ (Ferrucci, ined.) para una de sus especies reafirmaría su condicióin primitiva. Este número no estaba registrado para la tribu, sin embargo se conocía para Allophylus - Thouinieae (Fritsch, 1970, Bawa, 1973, Ferrucci, 1985). Thinouia comparte el fruto esquizocárpico con Lophostigma, Houssayanthus y Serjania.

Lophostigma, vcuparía una posición un poco más evolucionada compartiendo con el resto de los géneros las flores cigomorfas, con corola tetrámera y pétalos con escama basal petaloidea, simétrica en los pétalos superiores y asimétrica en los pétalos laterales. El nectario reducido a un hemidisco la diferencia de los géneros restantes. 
Tabla 1. Caracterización macromorfológica, citológica y palinológica de los géneros de Paullinieae

\begin{tabular}{|c|c|c|c|c|c|c|c|c|}
\hline Géneros Caracteres & $\begin{array}{l}\text { Simetría } \\
\text { floral }\end{array}$ & Cáliz & Corola & $\begin{array}{c}\text { Escama de los } \\
\text { pétalos }\end{array}$ & $\begin{array}{l}\text { Nectario } \\
\text { floral }\end{array}$ & Tipo de fruto & $2 n$ & Tipo de polen \\
\hline Thinouia & $X$ & (5) & 5 & $\begin{array}{l}\text { Soldada a la } \\
\text { uña, porción } \\
\text { libre bipartida }\end{array}$ & Disco & $\begin{array}{l}\text { Mericarpos } \\
\text { samaroideos, } \\
\text { ala ascendente }\end{array}$ & 28 & Tricolporado \\
\hline Lophostigma & & 5 & & & Hemidisco & $\begin{array}{l}\text { Mericarpos } \\
\text { samaroideos, }\end{array}$ & - & $\begin{array}{l}\text { Sincolporado, } \\
\text { heterocolpado, } \\
\text { dicolpo-diorado, } \\
\text { monocolpado }\end{array}$ \\
\hline Serjania & & $\begin{array}{c}5 \\
\text { ó } \\
3+(2)\end{array}$ & & & $\begin{array}{l}\text { Glándulas } \\
4\end{array}$ & ala descendente & 24 & \\
\hline Houssayanthus & $\%$ & 5 & 4 & $\begin{array}{l}\text { Escama } \\
\text { basal } \\
\text { petaloidea }\end{array}$ & 4 & $\begin{array}{l}\text { Mericarpos sub- } \\
\text { semicirculares, } \\
\text { rodeados de un } \\
\text { ala }\end{array}$ & 24 & \\
\hline Urvillea & & $\begin{array}{c}5 \\
\text { ó } \\
3+(2)\end{array}$ & & & 4 & & $\begin{array}{l}22 \\
44\end{array}$ & $\begin{array}{l}\text { Hemitrisincol- } \\
\text { porado }\end{array}$ \\
\hline Cardiospermum & & $\begin{array}{l}4 \\
6 \\
5\end{array}$ & & & $\begin{array}{l}4 \\
0 \\
2\end{array}$ & $\begin{array}{l}\text { Cápsula } \\
\text { septífraga }\end{array}$ & $\begin{array}{l}14 \\
20 \\
22\end{array}$ & \\
\hline Paullinia & & $\begin{array}{c}5 \\
\text { ó } \\
3+(2)\end{array}$ & & & 4 & & 24 & Triporado \\
\hline
\end{tabular}


Serjania, Houssayanthus, Urvillea, Cardiospermum y Paullinia comparten la presencia de 4 glándulas nectaríferas o 2 por reducción como en especies de Cardiospermum. Serjania y Houssayanthus sólo se diferencian por la forma del mericarpo, ya que comparten todos los demás caracteres, aún el número cromosómico.

Urvillea y Cardiospermum, que comparten con Paullinia el fruto tipo cápsula, tienen $2 \mathrm{n}=22,44$, y $2 \mathrm{n}=14,20,22$ respectivamente. Paullinia registra $2 n=24$.

\section{Conclusiones}

Sobre la base de los resultados obtenidos en el presente trabajo, se propone una modificación a la hipótesis sobre la tendencia evolutiva postulada para la tribu Paullinieae por Muller \& Leenhouts (1976). En la Figura 5 se aprecia a la izquierda la interpretación filogenética de los autores citados, y a la derecha nuestra propuesta. La posibilidad de estudiar el polen de Houssayanthus, género fundado por Hunziker (1978), nos permite tener representados a los 7 géneros con que cuenta la tribu.

El tipo de apertura y la forma que presentan los granos de polen de los géneros estudiados, nos lleva a coincidir con Muller \& Leenhouts en considerar el grano subesferoidal-tricolporado característico de Thinouia como el tipo más primitivo dentro de la tribu. A partir del grano tricolporado, por dos líneas evolutivas independiente se habrían diferenciado, por un lado, el grano prolato-heterocolpado exclusivo de Lophostigma, y por el otro el grano oblato o peroblato, hemitricolporado que comparten los géneros Serjania, Houssayanthus, Urvillea y Cardiospermum. En un paso evolutivo posterior, con reducción de las ectoaperturas se llegaría al grano triporado de Paullinia.

Los caracteres palinológicos están correlacionados en buen grado con los caracteres macromorfológicos de flor y fruto, y datos cromosómicos que caracterizan a los géneros de esta tribu (Tabla 1).

Apoyamos la hipótesis de Muller \& Leenhouts (1976) de que entre el tipo de polen tricolporado, de Thinouia y el tipo hemitrisincolporado debe haber existido un tipo de polen sincolporado breviaxil, ancestral para la 


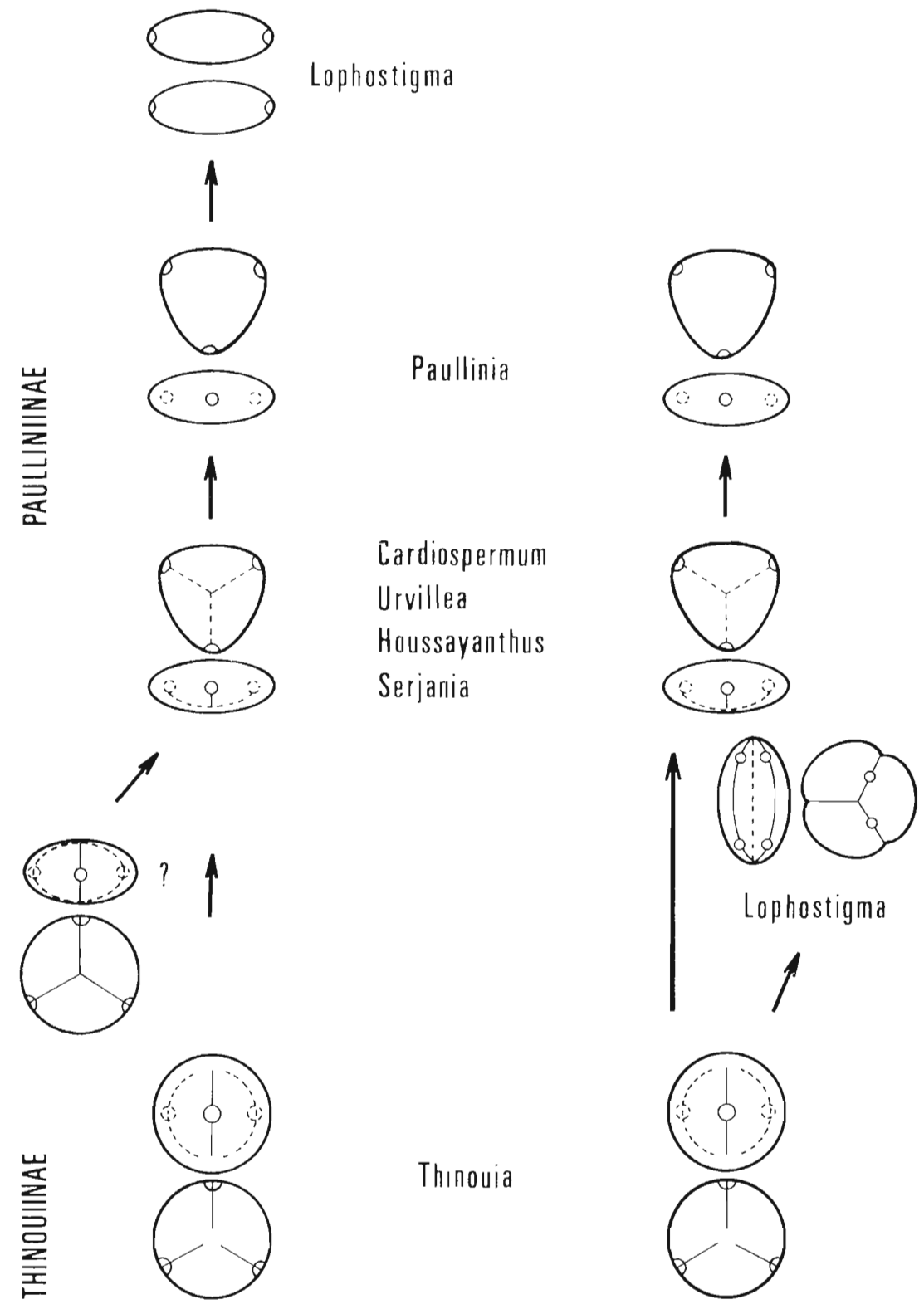

Fig. 5. Representación gráfica de la tendencia evolutiva propuesta para la tribu basada en tipos de polen en relación a la taxonomía. A la izquierda el esquema publicado por Muller \& Leenhouts (1976), a la derecha la interpretación propuesta en este trabajo. 
tribu. No compartimos la propuesta de Ham sobre el probable origen de Paullinieae a partir de Cupanieidites.

\section{Agradecimientos}

Agradecemos al Ing. Agr. A. Krapovickas, Dra. C. Cristóbal y a la Lic. S. Tressens la lectura crítica del manuscrito y al Sr. V. Maruñak por el montado de las figuras.

\section{Bibliografía}

Acevedo-Rodríguez, P. A revision of Lophostigma Radlk. (Sapindaceae). Syst. Bot. (en prensa).

Anzótegui, L. M. \& M. S. Ferrucci. 1992. Sapindaceae, fichas 1-22. En: S. M. Pire, L. M. Anzótegui y G. A. Cuadrado eds., Atlas palinológico del nordeste argentino. D'Orbignyana 7.

Barros, M. M. 1969. Pólem das plantas silvestres do Ceará. II. Municipio de Fortaleza - Familias Ochnaceae, Simarubaceae e Sapindaceae. Bol. cearense Agron. 10: 53-58, figs. I-14.

Baum, B. R., I. J. Bassett \& C. W. Crompton. 1971. Pollen morphology of Tamarix species and its relationship to the taxonomy of the genus. Pollen \& Spores 13 (4): 495-521, pl. 1-2.

Bawa, K. S. 1973. Chromosome numbers of tree species of a lowland tropical community. J. Arnold Arbor. 54: 422-434.

Berg, R. G. Van den. 1978. Pollen morphology of the genera Pometia, Cubilia, Otonephelium, and Litchi (Sapindaceae-Nephelieae). Blumea 24 (2): 369-394, pl. 1-9.

Cruz, M.A.V. \& T. S. Melhem. 1984. Estudos polínicos em Sapindaceae. Revista Brasil. Bot. 7: 5-25, figs. 1-34.

Erdtman, G. 1966. Pollen morphology and plant taxonomy. Angiosperms. New York.

Ferrucci, M. S. 1985. Recuentos cromosómicos en Allophylus y Serjania (Sapindaceae). Bol. Soc. Argent. Bot. 24 (1-2): 200-202, fig. 1.

- 1993. Una nueva especie y una nueva combinación en Cardiospermum (Sapindaceae). Bonplandia 6 (4): 245-259. 
Fritsch, R. 1970. Chromosomenzahlen von Pflanzen der Insel K. I. Kulturpflanze 18: 189-197.

Ham, R.W.J.M. Van der. 1977. Pollenmorphology of the genus Mischocarpus (Sapindaceae). Blumea 23 (2): 301-335, figs. 1-2, pl. $1-16$.

- 1989. Evolutionary trends in the morphology and harmomegathy of the pollen of the genus Guioa (Sapindaceae-Cupanieae). Blumea 34(1): $21-60$, figs. 1-8, pl. 1-9.

- 1990. Nephelieae pollen (Sapindaceae): Form, function and evolution. 255 p. Leiden. Rijksherbarium/Hortus Botanicus.

Hunziker, A. T. 1978. Notas críticas sobre Sapindáceas Argentinas. III. Houssayanthus, genus novum Sapindacearum. Kurtziana 11: 7-24, figs. $1-5$.

Kremp, G.O.W. 1968. Morphologic Encyclopedia of Palynology. The University of Arizona Press. Tucson.

Melhem, T. S. \& A. C. Campos. 1969. Pollen grains of plants of the "Cerrado". XXIII. Icacinaceae, Martyniaceae and Sapindaceae. Ann. Acad. Brasil. Sci. 41 (3): 471 -483, figs. 1-37.

Merville, M. 1965. Le pollen des Sapindacées d'Afrique occidentale. Pollen \& Spores 7 (3): 465-489, pl. $1-4$.

Muller, J. 1970. Pollen morphology of the genus Lepisanthes (Sapindaceae) in relation to its taxonomy. Blumea 18 (2): 507-561, figs. 16, pl. $1-19$.

- 1971. Pollenmorphological notes on the genus Dimocarpus (Sapindaceae). Blumea 19 (1): 133-145, figs. 1-2, pl. 1-4.

- 1979. Form and function in angiosperm pollen. Ann. Missouri Bot. Gard. 66 (4): 593-632, figs. 1-13.

- 1985. Pollen morphology of the genus Harpullia (SapindaceaeHarpullieae). Blumea 31 (1): 161-218, figs. 1-2, pl. 1-19.

Muller, J. \& P. W. Leenhouts. 1976. A general survey of pollen ty r's in Sapindaceae in relation to taxonomy. In: I. K. Ferguson \& J. Vuller, The evolutionary significance of the exine. Linnean Soc. Symp. Ser. 1: 407-495, figs. 1-5, t. 1-2, pl. 1-12.

Muller, J. \& M. Schuller. 1989. Fam. 120: Sapindaceae. In: H. Straka, 
Palynologica Madagassica et Mascarenica. Tropische und subtropische Pflanzenwelt 67: 99-137, pl. 1-12.

Radlkofer, L. 1897. Sapindaceae, in Engler \& Prantl, Die Natürlichen Pflazenfamilien. Nachtr. 1: 228.

-. 1931-1934. Sapindaceae, in Engler, Das Pflanzenreich 4 (165): 11539, figs. $1-46$.

Salgado-Labouriau, M. L. 1973. Contribuição à palinologia dos cerrados.

291 p. Rio de Janeiro. Academia Brasileira de Ciências.

Selling, O. H. 1947. Studies in Hawaiian pollen statistics pt. II. pp. 218 226. Dato tomado de Wang \& Chien, 1956. Bïshop Museum, Honolulu.

Van Campo, M. 1957. Palynologie africaine I. Bull. IFAN 19, sér. A (3): 659-678, pl. 1-24.

-. 1958. Palynologie africaine II. Bull. IFAN 20 sér. A(3): 753-760, pl. 25-48.

- 1976. Patterns of pollen morphological variation within taxa. In: I. K. Ferguson \& J. Muller, The evolutionary significance of the exine. Linnean Soc. Symp. Ser. 1: 125-137, figs. 1-3, pl. 1.

Walker, J. W. \& J. A. Doyle. 1975. The bases of angiosperm phylogeny: Palynology. Ann. Missouri Bot. Gard. 62 (3): 664-723, figs. 1-20. Wang, F. M. \& N. F. Chien. 1956. A contribution to the pollen morphology of Sapindaceae. Acta Bot. Sin. 5: 327-338.

\section{Post Scriptum}

Después de entregado el manuscrito, se publicó el trabajo de Beck: Chimborazoa (Sapindaceae), a new genus from Ecuador. Brittonia 44 (3): 306-311, figs. 1-2. 1992. El género descripto pertenece a la tribu Paullinieae. La descripción de los granos de polen permite incluir este género en el esquema evolutivo propuesto para la tribu en nuestro trabajo. Chimborazoa comparte el tipo de granos hemitrisincolporados con los géneros Serjania, Houssayanthus, Urvillea y Cardiospermum. Se diferencia de los géneros más afines Houssayanthus y Serjania sólo por el carpóforo no persistente y los cocos ápteros. 